\title{
Elevation of Serum Cytokines Preceding Elevation of Liver Enzymes in a Case of Drug-Induced Liver Injury
}

\author{
Keisuke Kakisaka 1)2) \\ Yasuhiro Takikawa ${ }^{2)}$ \\ 1) Department of Gastroenterology, Kazuno Kosei Hospital, \\ Kazuno, Japan
}

2) Division of Gastroenterology and Hepatology, Department of Internal Medicine, Iwate Medical University,

Morioka, Japan

Key words: IL-1 $\beta$, TNF- $\alpha$, MCP-1, Bio-Plex

Address for correspondence: $\quad$ Keisuke Kakisaka, M.D., Ph.D.

School of Medicine

Iwate Medical University

19-1 Uchimaru Morioka

Iwate, JAPAN 0208505

Tel.: +81-19-651-5111

Fax: +81-19-652-6664

E-mail:keikaki@iwate-med.ac.jp

Running title: Serial Changes in the Cytokines Levels during DILI

Number of:

Figures - 2

Table -2

Supplemental figure -1

References - 12

Abbreviations: alanine aminotransferase (ALT), aspartate aminotransferase (AST),

alkaline phosphatase (ALP), drug-induced liver injury (DILI), drug lymphocytes 
stimulation test (DLST), gamma-glutamyltransferase ( $\gamma$-GTP), interleukin (IL),

monocytic chemotactic protein 1 (MCP-1), macrophage inflammatory protein-1 beta (MIP-1 $\beta$ ), total bilirubin (T-BIL), white blood cell (WBC) 


\section{Abstract}

A 50-year-old male who was being treated for both pneumonia and type 2 diabetes mellitus complained of abdominal distention on the $16^{\text {th }}$ hospital day. Liver enzyme elevation without symptoms was detected on the $17^{\text {th }}$ hospital day. Based on a Roussel Uclaf Causality Assessment Method score of 10 and a Japan Digestive Disease Week score of 9, we diagnosed the patient with drug-induced liver injury (DILI).

Simultaneous assays of the levels of cytokines revealed that the elevation of the levels of interleukin (IL) - 1 $\beta, \mathrm{IL}-10, \mathrm{IL}-12, \mathrm{IL}-13$ and tumor necrosis factor alpha preceded the elevation of the serum liver enzymes. This case suggests that some cytokines or related molecules are potentially useful as early-phase biomarkers for DILI.

\section{Introduction}

Drug-induced liver injury (DILI) is the most common cause of death from acute liver failure in the United States (1) and has become a serious health problem. In order to predict and treat DILI, the detailed mechanisms underlying its development must be clarified. However, the pathogenesis of DILI remains unclear because the diagnosis is usually retrospective.

A subset of patients with DILI present with clinical findings associated with allergic reactions, such as rashes or eosinophilia (2). These reactions in patients with DILI are 
associated with several cytokines $(3,4)$. Therefore, cytokine interactions may play an important role in the pathogenesis of DILI.

\section{Case report}

A 50-year-old male who was being treated for type 2 diabetes mellitus and alcoholic liver injury with insulin by a general physician visited our department complaining of dyspnea and pyrexia. Moist rales were detected in the left lower lung. Cardiac and abdominal examinations were unremarkable. The laboratory data revealed leukocytosis, liver injury and hyperbilirubinemia: white blood cell (WBC) count: 14,700/mL, alanine aminotransferase (ALT): 225 IU/L and gamma-glutamyltransferase ( $\gamma$-GTP): 1,090 IU/L. Chest radiography revealed an infiltrative shadow accompanied by an air bronchogram in the right upper lobe. The patient was diagnosed with alcoholic liver injury and pneumonia. The pneumonia was treated with several antibiotics: tazobactam/ piperacillin (TAZ/ PIPC, 9 g/day) from the $1^{\text {st }}$ hospital day to the $7^{\text {th }}$ hospital day, micafungin (MCFG, $75 \mathrm{mg} /$ day) from the $8^{\text {th }}$ hospital day to the $17^{\text {th }}$ hospital day and levofloxacin (LVFX, $500 \mathrm{mg} /$ day) from the $8^{\text {th }}$ hospital day to the $17^{\text {th }}$ hospital day. On the $15^{\text {th }}$ hospital day, the pneumonia improved and the liver enzyme level returned to normal. However, the patient complained of right upper abdominal distention on the $16^{\text {th }}$ hospital day. Although this symptom rapidly disappeared after four hours, 
asymptomatic liver injury was detected on the 17th hospital day: ALT: 666 IU/L, $\gamma$-GTP:

621 IU/L and alkaline phosphatase: 2,113 IU/L (Figure 1 and Table 1). No causes of acute liver injury, such as cholelithiasis, viral infection or autoimmune disease, were detected (Supplemental Figure 1 and Table 1). Therefore, a diagnosis of DILI due to antibiotics was suspected, and all medications were discontinued, except for insulin. The liver enzyme elevation improved by the $22^{\text {nd }}$ hospital day without specific therapy, and the patient was discharged on the $26^{\text {th }}$ hospital day. Although drug lymphocytes stimulation test (DLST) was performed to TAZ/ PIPC, MCFG and LVFX, DLST for all these medicines was negative.

The Roussel Uclaf Causality Assessment Method score in this case was 10 and the Japan Digestive Disease Week score was 9 (Table 2). According to the patient's clinical course, the antibiotics were considered to be the causal drugs (Figure 1). Serum samples were collected on the $15^{\text {th }}$ hospital day, when the serum liver enzyme levels were within the normal limits and it was two days before marked elevation in the liver enzymes levels was observed. Serial changes in the cytokine levels were simultaneously evaluated with the Bio-Plex 200 (BioRad, Tokyo, JAPAN), and the values were calculated using the Bio-Plex manager software program, version 5.0 (BioRad, Tokyo, JAPAN). The levels of IL-1 $\beta$, IL-10, IL-12, IL-13 and TNF- $\alpha$ were elevated before the 
liver enzyme elevation (Figure 2). The levels of IL-4, IL-5, IL-6, IL-8, IL-17, monocytic chemotactic protein 1 (MCP-1) and macrophage inflammatory protein-1 beta (MIP-1 $\beta$ ) immediately became elevated after the liver enzyme elevation and then dramatically decreased two to three days after peaking (Figure 2).

\section{Discussion}

DILI is classified into two types: the intrinsic type and the idiosyncratic type $(2,5,6)$.

Most cases of DILI are idiosyncratic, accounting for $13 \%$ of cases of acute liver failure in the US (1). In order to prevent and treat idiosyncratic DILI, the pathogenesis of the condition must be understood. However, because DILI is usually diagnosed retrospectively, the detailed mechanisms underlying the development of DILI remain unclear. Because a subset of idiosyncratic DILI patients present with rashes, fever or eosinophilia, the disease is considered to be associated with the immune response (2). Therefore, cytokine interactions may play an important role in the pathogenesis of

\section{DILI.}

We first reported the simultaneous evaluation of serial changes in the levels of several cytokines before the initiation of liver injury in humans and found that the elevation of the IL-1 $\beta$, IL-10, IL-12, IL-13 and TNF- $\alpha$ levels preceded the liver enzyme elevation. These findings suggest that these cytokines play important roles in the initial stage of 
DILI. Because alcoholic liver injury and pneumonia were present as preexisting diseases in this case, the levels of several cytokines were not within the normal ranges on the $15^{\text {th }}$ hospital day, although the patient was asymptomatic. Because we didn't store any samples before the $15^{\text {th }}$ hospital day in this case, we were not able to ascertain what cytokine was initiation cytokine in onset of DILI. Sustained high levels of several cytokines in patients with pneumonia or alcoholic liver injury after treatment have been previously reported (7-10). Therefore, the influence of alcoholic liver injury and pneumonia on the cytokine levels cannot be completely excluded in this case. In fact, the levels of most cytokines in this case were high to normal even in 52 day after the administration of treatment (11). However, the levels of several cytokines that were high before onset immediately decreased after the administration of antibiotics was discontinued as shown the profile of IL-1 $\beta$. Therefore, these cytokines acted as preconditioning cytokines in this case.

We hypothesized the following mechanism of liver injury in the present case. Because IL-1 $\beta$ and TNF- $\alpha$, which are proinflammatory cytokines, were at a high level before the elevation of liver enzymes, these cytokines functioned as preconditioning cytokines. IL-10, an anti-inflammatory cytokine, was also at a high level at that time. The IL-10 level may be elevated as a reaction to high levels of proinflammatory cytokines. The 
IL-1 $\beta$, TNF- $\alpha$ and IL-10 levels were decreased after the administration of antibiotics was discontinued. In contrast, the elevation of IL-12, which is secreted from activated hepatocytes, and IL-13, which is secreted from Th2 cells, was sustained at a high level for several days after the elevation of the liver enzymes. However, the role of sustained high levels of IL-12 and IL-13 remains unclear. Several cytokines originating from Th2 cells, such as IL-4, IL-5 and IL-6, in addition to IL-17 from Th17 cell, and several chemokines, such as IL-8, MCP-1 and MIP-1 $\beta$, were increased following the elevation of liver enzymes and rapidly decreased after several days of elevation of liver enzymes. Therefore, these cytokines and chemokines may have been elevated as enhanced or inhibited factors due to the influence of IL-1 $\beta$, TNF- $\alpha$ and IL-10. Because IL-1 $\beta$, TNF- $\alpha$ and IL-10 were secreted from macrophage or antigen-presenting cell, these cells played an initial important role in the development of liver enzyme elevation in this case.

Intriguingly, the inhibition of IL-1 $\beta$ was found to attenuate liver damage in an animal model of DILI (12). IL-10 and TNF- $\alpha$ polymorphisms are associated with DILI (4). The identification of early-phase biomarkers for DILI is urgently needed because the prognosis of patients with overt idiosyncratic DILI remains very poor. The present case report therefore suggests that early-phase cytokines or some related molecules may be potentially useful as early-phase biomarkers for DILI. Although interaction between 
preceding inflammatory diseases and the cytokines at the onset of DILI and the mechanisms through which cytokines interact in patients with DILI remain unclear, this case report may provide new insight into the initial stages of DILI. 


\section{Acknowledgements}

The authors who have taken part in this study declared that they do not have anything to declare regarding funding from industry or conflict of interest with respect to this manuscript. 
References

1. Ostapowicz G, Fontana RJ, Schiodt F'V, Larson A, Davern TJ, Han SH, McCashland TM, et al. Results of a prospective study of acute liver failure at 17 tertiary care centers in the United States. Ann Intern Med 2002;137:947-954.

2. Tujios S, Fontana RJ. Mechanisms of drug-induced liver injury: from bedside to bench. Nat Rev Gastroenterol Hepatol 2011;8:202-211.

3. Malatjalian DA, Ross JB, Williams CN, Colwell SJ, Eastwood BJ. Methotrexate hepatotoxicity in psoriatics: report of 104 patients from Nova Scotia, with analysis of risks from obesity, diabetes and alcohol consumption during long term follow-up. Can J Gastroenterol 1996;10:369-375.

4. Pachkoria K, Lucena MI, Crespo E, Ruiz-Cabello F, Lopez-Ortega S, Fernandez MA, Romero-Gomez M, et al. Analysis of IL-10, IL-4 and TNF-alpha polymorphisms in drug-induced liver injury (DILI) and its outcome. J Hepatol 2008;49:107-114.

5. Bell LN, Chalasani N. Epidemiology of idiosyncratic drug-induced liver injury. Semin Liver Dis 2009;29:337-347.

6. Grant LM, Rockey DC. Drug-induced liver injury. Curr Opin Gastroenterol 2012;28:198-202.

7. Antunes G, Evans S, Lordan J, Frew A. Systemic cytokine levels in community-acquired pneumonia and their association with disease severity. The European respiratory journal 2002;20:990-995.

8. Felver M, Mezey E, McGuire M, Mitchell M, Herlong H, Veech G, Veech R. Plasma tumor necrosis factor alpha predicts decreased long-term survival in severe alcoholic hepatitis. Alcoholism, clinical and experimental research 1990;14:255-259.

9. Hart JP, Broadwater G, Rabbani Z, Moeller BJ, Clough R, Huang D, Sempowski $G A$, et al. Cytokine profiling for prediction of symptomatic radiation-induced lung injury. Int J Radiat Oncol Biol Phys 2005;63:1448-1454.

10. Kellum J, Kong L, Fink M, Weissfeld L, Yealy D, Pinsky M, Fine J, et al. Understanding the inflammatory cytokine response in pneumonia and sepsis: results of the Genetic and Inflammatory Markers of Sepsis (GenIMS) Study. Archives of internal medicine 2007;167:1655-1663.

11. Yasumi Y, Takikawa Y, Endo R, Suzuki K. Interleukin-17 as a new marker of severity of acute hepatic injury. Hepatology research : the official journal of the Japan Society of Hepatology 2007;37:248-254.

12. Yano A, Higuchi S, Tsuneyama K, Fukami T, Nakajima M, Yokoi T. Involvement of immune-related factors in diclofenac-induced acute liver injury in mice. Toxicology 2012;293:107-114. 


\section{FIGURE LEGENDS}

Figure 1. Time course of the laboratory data of the present patient with

drug-induced liver injury. The upper line chart presents several biochemical parameters, including the levels of aspartate aminotransferase (AST), alanine aminotransferase (ALT), alkaline phosphatase (ALP), gamma-glutamyltransferase ( $\gamma$-GTP) and total bilirubin (T-BIL). The lower line chart presents the white blood cell (WBC) count and the proportion of cells exhibiting eosinophilia relative to the total number of WBCs. The bar chart indicates the duration of each antibiotic.

Figure 2. Simultaneous evaluation of serial changes in the levels of several cytokines before the onset of drug-induced liver injury. The line charts indicate the serial changes in the levels of cytokines evaluated using BioPlex, including interleukin (IL)-1 $\beta$, IL-4, IL-5, IL-6, IL-8, IL-10, IL-12, IL-13, IL-17, monocytic chemotactic protein 1 (MCP-1), macrophage inflammatory protein-1 beta (MIP-1 $\beta)$ and tumor necrosis factor alpha $(\mathrm{TNF}-\alpha)$. We collected serum samples on the 15 th, 17 th $, 18^{\text {th }}, 19^{\text {th }}, 22^{\text {nd }}, 23^{\text {rd }}, 24^{\text {th }}$, $26^{\text {th }}, 33^{\text {rd }}$ and $52^{\text {nd }}$ days. The normal ranges of several cytokines have been previously reported by us. The normal range of IL-1ß, IL-4, IL-5, IL-6, IL-8, IL-10, IL-12, IL-13, IL-17 and TNF- $\alpha$ is up to $2.0 \mathrm{pg} / \mathrm{mL}$. The normal range of MCP- 1 or MIP- $1 \mathrm{~b}$ is up to $174.8 \mathrm{pg} / \mathrm{mL}$ or up to $159.3 \mathrm{pg} / \mathrm{mL}$, respectively. 
Supplemental Figure Legend

Supplemental figure 1. Imaging findings of the present patient with drug-induced liver injury on the $17^{\text {th }}$ hospital day. (a) Abdominal computed tomography (CT) showed mild splenomegaly and without dilatation of the intrahepatic biliary ducts.

(b) Magnetic resonance cholangiopancreatography showed no evidence of obstructive jaundice or cholelithiasis . 
Figure 1.

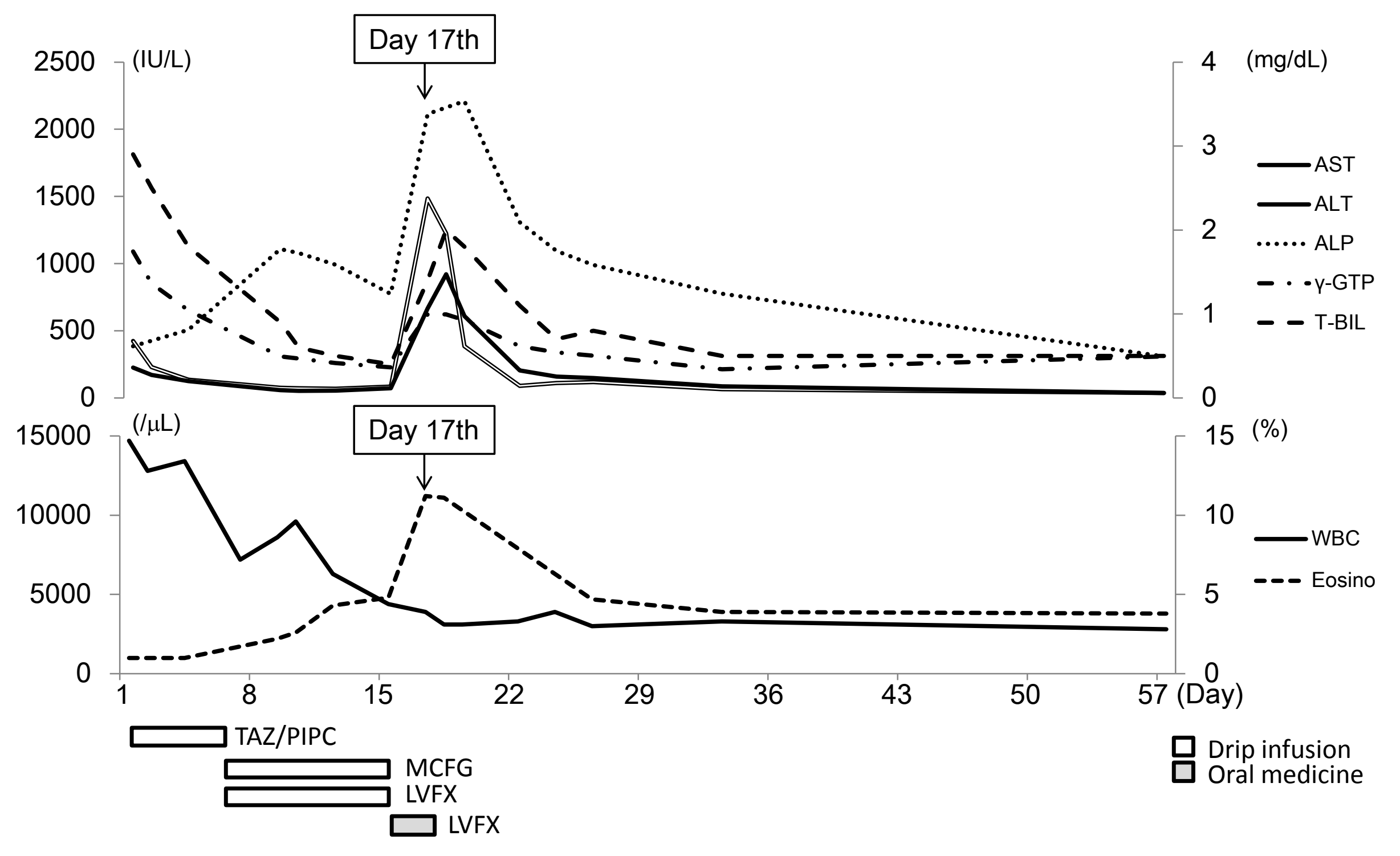


Supplemental figure 1.

(a)

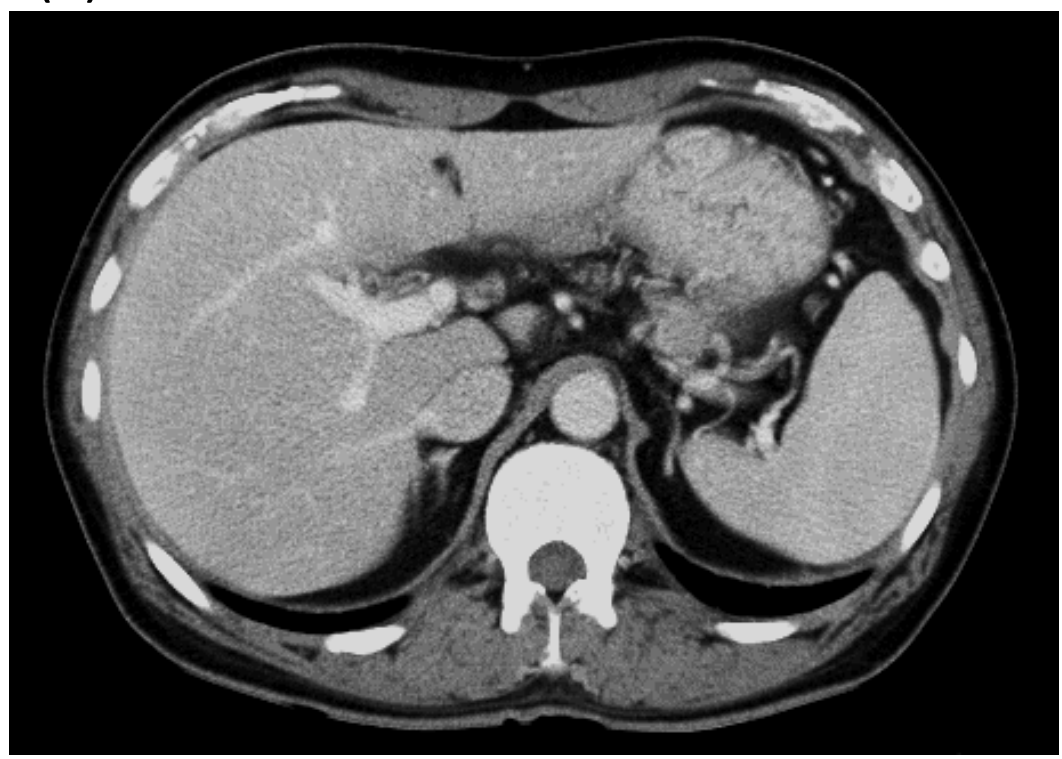

(b)

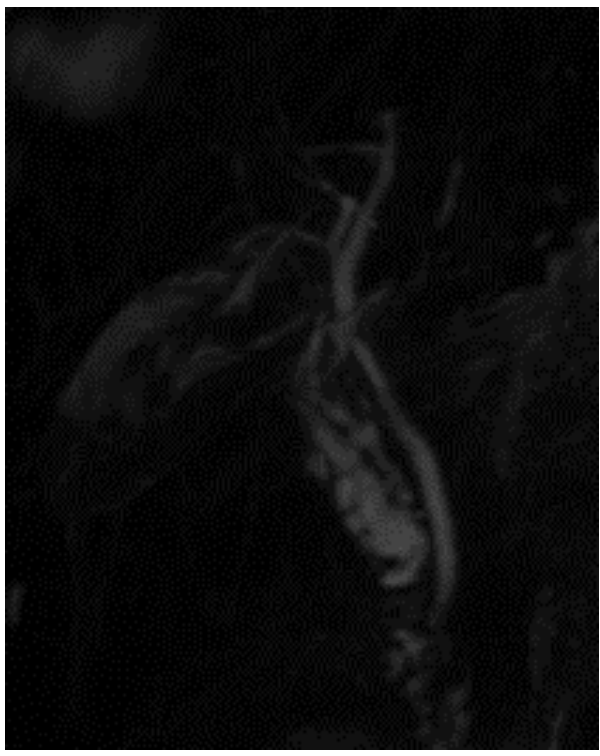


Table. 1 Laboratory data of the present patient with drug-induced liver injury on the 1st and 17th hospital days.

Administration

\begin{tabular}{|c|c|c|c|c|c|}
\hline Hematology & & & Virus markers & & \\
\hline WBC & 14.7 & $10^{3} / \mathrm{mL}$ & $\mathrm{HBsAg}$ & $(-)$ & \\
\hline Neutro & 81.2 & $\%$ & HCVAb & $(-)$ & \\
\hline Lympho & 16.6 & $\%$ & $\lg M \mathrm{HA}$ & $(-)$ & \\
\hline Mono & 1.9 & $\%$ & HSV IgM & $(-)$ & \\
\hline Eosino & 0.1 & $\%$ & HSV IgG & $(+)$ & \\
\hline Baso & 0.1 & $\%$ & CMV IgM & $(-)$ & \\
\hline $\mathrm{RBC}$ & 412 & $10^{6} / \mathrm{mL}$ & CMV IgG & $(+)$ & \\
\hline $\mathrm{Hb}$ & 13.9 & $\mathrm{~g} / \mathrm{dL}$ & EBVCA IgG & $(-)$ & \\
\hline PIt & 99 & $10^{3} / \mathrm{mL}$ & EBVCA IgM & $(-)$ & \\
\hline & & & EBNA Ab & $(-)$ & \\
\hline Blood chemis & & & & & \\
\hline $\mathrm{TP}$ & 6.6 & $\mathrm{~g} / \mathrm{dL}$ & Autoantibodies & & \\
\hline Albumin & 3.3 & $\mathrm{~g} / \mathrm{dL}$ & ANA & $<x 40$ & \\
\hline T-Bil & 2.9 & $\mathrm{mg} / \mathrm{dL}$ & AMA & $(-)$ & \\
\hline AST & 424 & IU/L & & & \\
\hline ALT & 225 & IU/L & Tumor markers & & \\
\hline ALP & 385 & IU/L & CEA & 2.1 & $\mathrm{ng} / \mathrm{mL}$ \\
\hline$\gamma$-GTP & 1090 & IU/L & CA19-9 & 17.3 & $\mathrm{U} / \mathrm{mL}$ \\
\hline ChE & 138 & IU/L & AFP & 2.3 & $\mathrm{ng} / \mathrm{mL}$ \\
\hline BUN & 22.6 & $\mathrm{mg} / \mathrm{dL}$ & PIVKA-2 & 21 & $\mathrm{mAU} / \mathrm{mL}$ \\
\hline Cre & 1.23 & $\mathrm{mg} / \mathrm{dL}$ & & & \\
\hline AMY & 33 & IU/L & & & \\
\hline $\mathrm{NH} 3$ & 57 & $\mathrm{mg} / \mathrm{dL}$ & & & \\
\hline CRP & 36.13 & $\mathrm{mg} / \mathrm{dL}$ & & & \\
\hline
\end{tabular}

17th hospital day

\begin{tabular}{ccl}
\hline Hematology & & \\
WBC & 3.1 & $10^{3} / \mathrm{mL}$ \\
Neutro & 44.0 & $\%$ \\
Lympho & 33.1 & $\%$ \\
Mono & 8.0 & $\%$ \\
Eosino & 11.1 & $\%$ \\
Baso & 3.8 & $\%$ \\
RBC & 447 & $10^{6} / \mathrm{mL}$ \\
Hb & 14.4 & $\mathrm{~g} / \mathrm{dL}$ \\
Plt & 369 & $10^{3} / \mathrm{mL}$
\end{tabular}

Blood chemistry

$\begin{array}{ccl}\text { TP } & 6.8 & \mathrm{~g} / \mathrm{dL} \\ \text { Albumin } & 3.4 & \mathrm{~g} / \mathrm{dL} \\ \text { T-Bil } & 1.2 & \mathrm{mg} / \mathrm{dL} \\ \text { AST } & 1484 & \mathrm{IU} / \mathrm{L} \\ \text { ALT } & 666 & \mathrm{IU} / \mathrm{L} \\ \text { ALP } & 2113 & \mathrm{IU} / \mathrm{L} \\ \gamma \text {-GTP } & 621 & \mathrm{IU} / \mathrm{L} \\ \text { ALP } & 2113 & \mathrm{IU} / \mathrm{L} \\ \text { BUN } & 10.8 & \mathrm{mg} / \mathrm{dL} \\ \text { Cre } & 1.03 & \mathrm{mg} / \mathrm{dL} \\ \text { AMY } & 97 & \mathrm{IU} / \mathrm{L} \\ \text { NH3 } & 36 & \mathrm{mg} / \mathrm{dL} \\ \text { CRP } & 0.26 & \mathrm{mg} / \mathrm{dL}\end{array}$

$\begin{array}{ccl}\text { Blood coagulation } & \\ \text { PT } & 65 & \% \\ \text { HPT } & 54 & \% \\ \text { Fib } & 643 & \mathrm{mg} / \mathrm{dL} \\ \text { FDP } & 11.8 & \mathrm{mg} / \mathrm{mL}\end{array}$
Blood coagulation

$\begin{array}{ccl}\text { PT } & 72 & \% \\ \text { HPT } & 64 & \% \\ \text { Fib } & 406 & \mathrm{mg} / \mathrm{dL} \\ \text { FDP } & 2.1 & \mathrm{mg} / \mathrm{mL}\end{array}$

WBC, white blood cells; RBC, red blood cells; Hb, hemoglobin; Plt, pletelets; TP, total protein; T-Bil., total bilirubin; AST, aspartate aminotransferase; ALT, alanine aminotransferase; ALP, alkaline phosphatase; $\gamma$-GTP, $\gamma$-glutamyl transpeptidase; ChE, choline esterase; BUN, blood urea nitrogen; Cre, creatinine; AMY, amylase; CRP, C-reactive protein; PT, prothrombin time; HPT, hepaplastin test; Fib, fibrinogen; FDP, fibrin degradation products; Ig,

immunoglobulin; $A b$, antibody; $A g$, antigen; $H B$, hepatitis $B$ virus; $H C V$, hepatitis $C$ virus; $H A$, hepatitis $A$ virus; $H S V$, herpes simplex virus; $C M V$, cytomegalovirus; EB, Epstein-Barr virus; ANA, anti-nuclear antibody; AMA, anti-mitochondrial antibody; CEA, Carcinoembryonic antigen; CA19-9, carbohydrate antigen 19-9; AFP, $\alpha$-fetoprotein; PIVKA-II, protein induced by vitamin K absence/antagonist-II. 
Table. 2 Assessments used to diagnose drug-induced liver injury

\section{RUCAM score}

Type of liver injury

Cholestatic/mixed

Time of onset of the event First exposure

Time from drug intake unti reaction onset

5 to 90 days

Alcohol or pregnancy risk factor

Age risk factor

Present

$\geq 55$ years

Course of the reaction $\quad \geq 50 \%$ improvement 180 days

Exclusion of non drugrelated causes

Rule out

Previous information on hepatotoxicity

Reaction labeled in the product's characteristics

Total

\section{J-DDW score}

Type of liver injury

Cholestatic/mixed

Time of onset of the event Initial treatment

1

2

Time to onset

Risk factors

2

2

Search for non drug
causes
Previous information on
hepatotoxicity
Eosinophilia $(>6 \%)$
DLST

After cessation of the drug from the beginning of the drug

Presence of ethanol or pregnancy

Alcohol

Difference between the peak Decrease After cessation of the drug of ALP and upper limit of normal value

$>50 \%$ within 180 days

\begin{tabular}{lcc}
$\begin{array}{lcc}\text { All causes - groups I and II - } \\
\text { reasonably ruled out }\end{array}$ & Ruled out & 2 \\
$\begin{array}{l}\text { Reaction labelled in the } \\
\text { product characteristics }\end{array}$ & + & 1 \\
With eosinophilia & + & 1 \\
negative or unavailable & Negative & 0 \\
\hline & Total & 9
\end{tabular}

RUCAM, The Roussel Uclaf Causality Assessment Method; J-DDW, Japan Digestive Disease Week; DLST, drug lymphocyte stimulation test. 
Figure 2.
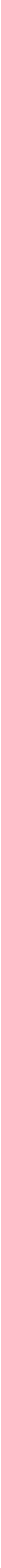